\title{
DIREITOS HUMANOS E DEMOCRACIA PARTICIPATIVA SOB A LÓGICA CAPITALISTA: UM DEBATE PARA REPENSAR O TRABALHO NA POLÍTICA DE ASSISTÊNCIA SOCIAL
}

\author{
HUMAN RIGHTS AND PARTICIPATORY DEMOCRACY UNDER CAPITALIST LOGIC: A \\ DEBATE TO RETHINK WORK IN SOCIAL ASSISTANCE POLICY
}

\author{
DERECHOS HUMANOS Y DEMOCRACIA PARTICIPATIVA BAJO LA LÓGICA \\ CAPITALISTA: UN DEBATE PARA RETENER EL TRABAJO EN LA POLÍTICA DE \\ ASISTENCIA SOCIAL
}

\author{
Cristiane Natalício de Souza ${ }^{1}$ \\ André Luís Duarte ${ }^{2}$
}

\begin{abstract}
Resumo
Este ensaio teórico problematiza o tema da democracia participativa como expressão dos direitos humanos na sociabilidade capitalista, assumindo a perspectiva de totalidade que se mantém na lógica processual, dialética e contraditória. O debate contextualiza a democracia das massas no processo de universalização dos direitos sociais, orientada pelo princípio da equidade e discute limites dessa institucionalização. Por fim, o texto apresenta apontamentos para ampliar as possibilidades de emancipação política em instâncias de deliberação pública e repensar a qualificação para o trabalho na política de assistência social.
\end{abstract}

Palavras-chave: Democracia Participativa. Direitos Humanos. Capitalismo.

\begin{abstract}
This theoretical essay problematizes the theme of participatory democracy as an expression of human rights in capitalist sociability, assuming the perspective of totality that are maintained in the procedural, dialectical and contradictory logic. The debate contextualizes mass democracy in the process of universalizing social rights, guided by the principle of equity and presents limits to this institutionalization. Finally, the text reflects on the setbacks of deliberative democracy and presents notes to expand the possibilities of political emancipation necessary for the redistribution of socially produced wealth.
\end{abstract}

Keywords: Participatory Democracy. Human rights. Capitalism.

\section{Resumen}

Este ensayo teórico problematiza el tema de la democracia participativa como expresión de los derechos humanos en la sociabilidad capitalista, asumiendo la perspectiva de totalidad que permanece en la lógica procesal, dialéctica y contradictoria. El debate contextualiza la democracia de masas en el proceso de universalización de los derechos sociales, guiado por el principio de equidad y discute los límites de esta institucionalización. Finalmente, el texto presenta notas para ampliar las posibilidades de emancipación política en casos de deliberación pública y repensar la calificación para trabajar en la política de asistencia social.

Palabras clave: Democracia participativa. Derechos humanos. Capitalismo.

\footnotetext{
1 Doutora em Ciências Sociais pela Pontifícia Universidade Católica de Minas Gerais, Brasil, com doutorado sanduíche na Universidad Autónoma Metropolitana Iztapalapa, México. Professora do Curso de Serviço Social da Universidade Federal de Viçosa, UFV. https://orcid.org/0000-0002-7534-2481 E-mail: cristiane.souza@ufv.br.

${ }^{2}$ Estudante do Curso de Serviço Social da Universidade Federal de Viçosa, UFV, MG, Brasil. https://orcid.org/0000-

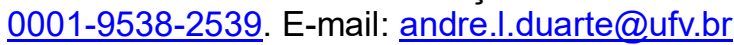




\section{INTRODUÇÃO}

O termo democracia foi usado pela primeira vez no século $V$ a.C., em Atenas, para designar o governo do povo que, na condição de cidadão, decidia em assembleias, por voto direto, sobre os assuntos políticos, econômicos e militares que envolviam a Grécia Antiga. Segundo Dahl (2012), a democracia partiu dessa cidade-estado para assumir outras configurações em vários estados nacionais, quando os cidadãos transferiram aos representantes políticos, eleitos por voto direto, a responsabilidade pelas decisões públicas. Essa mudança da democracia teve que ser articulada, conforme Dahl (2012), por causa das grandes extensões dos territórios nacionais que inviabilizam a forma de votação dos antigos.

No Brasil, a democracia começou a ser praticada com a Proclamação da República em 1889 e foi refreada em vários momentos até alcançar, em 1988, o seu estágio mais avançado. A maior ameaça à democracia nesse período teve início com o golpe de 1964, planejado por chefes militares e partidos políticos brasileiros, que impuseram a repressão e a censura político-cultural; instituíram as eleições indiretas e extinguiram os partidos políticos, fazendo retroceder conquistas importantes da democracia no Brasil, como o direito do voto secreto e o direito do voto feminino, garantidos com a promulgação da Constituição de 1934.

Foi também durante o regime militar, contudo, que o Estado teve que fortalecer as bases para a institucionalização da democracia participativa, em razão da desaceleração do ritmo de crescimento da economia na década de 1970; da necessidade de ofertar mais serviços sociais públicos para atender demandas crescentes da população nesse período; e da intenção dos governos, com poder enfraquecido, de ganhar adeptos. Em busca de criar "novos canais de representação de interesses", o governo militar apoiou "as eleições para cargos do poder executivo, a liberdade de imprensa, as associações, as organizações partidárias e os projetos e programas governamentais que previam criar conselhos formados por representantes da sociedade civil" (CÔRTES, 2005, p. 152), bem como "ampliar a provisão pública de bens e serviços às populações pobres e envolver esses usuários no processo de decisão política" (CÔRTES, 2005, p. 152).

Teve, também, grande importância na regulamentação da democracia participativa "a proposta liberalizante do cenário político internacional de racionalizar a administração pública," já que a aceitação dessa proposta pelo governo militar, para enfrentar a grande recessão econômica e fiscal da década de 1980 fortaleceu dois importantes movimentos desse período (CÔRTES, 2005, p. 152). De um lado, o movimento dos empresários, apoiadores do regime 
militar, que defendiam a "descentralização de competências do Estado e a ampliação da provisão privada de bens e serviços" para reduzir custos do governo. De outro lado, os movimentos sindical e popular, que buscavam nessa descentralização ter maior controle sobre as políticas públicas.

Foi a partir desse segundo movimento que os partidos de oposição à Ditadura Militar conquistaram hegemonia política e conseguiram assumir o poder em 1985. Desde então, a proposta de redemocratização do Brasil ganhou centralidade e a Constituição Federal foi promulgada em 1988, como importante marco de expressão da democracia brasileira (CODATO, 2005, p. 3). A democracia participativa foi institucionalizada a partir dessa lei e ampliada por leis complementares, normas e portarias que favoreceram a transferência de recursos federais aos municípios para atender demandas da área social, tornando mais frequentes os conselhos a partir de 1996 (GOHN, 2011, p. 92). A referida autora apresenta pesquisa realizada em 1998, informando que, "dos 1167 conselhos existentes nas áreas da educação, assistência social e saúde, 488 deles foram criados após 1997; 305 entre 1994 e 1996, e apenas 73 antes de 1991" (IDEM, 2011, p. 92).

Conforme Dagnino (2000) apud Luchmann (2006, p. 22), a democracia participativa foi regulamentada para compensar "os limites da democracia representativa em sua capacidade de produzir respostas adequadas aos problemas de exclusão e desigualdades sociais", já que na democracia representativa os cidadãos transferem aos representantes políticos, por voto direto, o direito de governar e, afastados da organização burocrática do governo, têm pouco controle sobre as decisões políticas.

Boschetti (2016) reconhece esses espaços de gestão descentralizada como importantes sistemas valorizados de luta em favor de direitos sociais, mas não deixa de enfatizar limites da democracia participativa, que surge como consequência da "reforma que amplia as funções do Estado na sociedade capitalista". Então, "ainda que resultante da luta da classe trabalhadora por melhores condições de vida e trabalho, a legislação social que garantiu a expansão dos direitos sociais tem uma funcionalidade política e econômica para o capital” (p. 47).

Os limites do atendimento às demandas da sociedade civil nessas instâncias públicas de decisão, segundo Côrtes (2005, p. 152), têm a ver com "a importância diferenciada das políticas sociais". Nos conselhos de saúde e educação, que deliberam sobre políticas universais, "a provisão de recursos tende a ser mais expansionista do que a provisão de recursos nos conselhos de assistência social que deliberam, sobre direitos destinados a atender grupos menos favorecidos da sociedade". 
Sob essa perspectiva, Carnelossi (2016) enfatiza fragilidades da democracia participativa que decide sobre políticas focalizadas e estabelece méritos para incluir as famílias merecedoras. Com esse encaminhamento, a autora problematiza a tendência dos conselhos municipais de Assistência Social de exigir dos usuários "participação em medidas de ativação voltadas ao mercado de trabalho" (MOSER, 2011, p. 3 apud CARNELOSSI, 2016, p. 2). Carnelossi (2016) denomina "Workfare" ${ }^{3}$ State a política social "criada nos Estados Unidos em 1960 para designar o bem-estar em troca ou à custa de trabalho". Essa política seleciona os seus usuários por "mérito competitivo e excludente" e tem como intenção criar "o hábito do trabalho, da busca resignada por empregos, além da submissão à disciplina dos rotineiros treinamentos profissionais exigidos por um mercado de trabalho inconstante".

Este ensaio teórico discute direitos humanos e democracia participativa sob a lógica da sociabilidade capitalista, em busca de refletir sobre a qualificação para o trabalho na política de assistência social. Assume, como ponto de partida, a perspectiva de totalidade que se mantém pela lógica processual, dialética e contraditória "das lutas de classes, do papel do Estado e do grau de desenvolvimento das forças produtivas" (BOSCHETTI, 2016, p. 25).

Muitos estudos têm condicionado o comprometimento da democracia nessas instâncias públicas de deliberação, à inexistência de paridade entre membros do governo e da sociedade civil organizada; à ausência de leis que "obriguem o Executivo a acatar as decisões dos conselhos"; à falta de fiscalização e controle sobre os atos dos conselheiros; à não divulgação das decisões que permeiam essas instâncias; ao aumento de demandas associadas à maior incidência dos conselhos gestores; ao desconhecimento do poder dos conselhos de "acionar o Ministério ao detectar alguma irregularidade" e à inexistência de capacitação técnica para melhor preparar os representantes da sociedade civil para participar dessa instância de decisão. Entretanto, pouca ênfase tem sido dada aos limites da democracia participativa associada aos direcionamentos dados à política de assistência social. Nesse sentido, para realizar esta discussão, tratou-se no tópico seguinte de discorrer sobre a democracia como expressão do capitalismo.

\section{DIREITOS HUMANOS E DEMOCRACIA PARTICIPATIVA SOB A LÓGICA CAPITALISTA}

Nesta parte do texto buscou-se contextualizar a democracia participativa a partir dos direitos humanos colocados a serviço da ordem burguesa e apresentar limites dos Conselhos

\footnotetext{
${ }^{3}$ De acordo com Carnelossi (2016, p. 2), o termo workfare foi criado nos Estados Unidos em 1960 "pela junção das palavras inglesas work (trabalho) e welfare (bem-estar).
} 
Municipais de Assistência, que buscam reduzir as desigualdades sociais por meio do trabalho. Em seguida, buscou-se argumentar sobre avanços e retrocessos da democracia nessas instâncias públicas de deliberação.

\section{Direitos civis, políticos e sociais no capitalismo}

A concepção dos direitos humanos (civis, políticos e sociais) "assenta-se na transformação da ordem estamentária feudal em ordem capitalista baseada em relações contratuais", que foi mobilizada pela acumulação primitiva e pela revolução burguesa", entre outros processos e revoluções (CERRONI, 1976 apud SIMÕES 2009, p. 65).

A acumulação primitiva foi indispensável à efetivação do capitalismo industrial, já que essa acumulação no século XVI assegurou a concentração de capital e a formação de uma massa de trabalhadores com opção apenas de vender o uso da sua força de trabalho (MARX, 2010). Essa disponibilidade de força de trabalho para a indústria se efetivou quando o produtor rural e o camponês foram expropriados de seus meios de sobrevivência, e os senhores feudais transformados em principais proprietários legais das terras.

A partir dessa expropriação, as terras produtivas de lavouras passaram a ser usadas como campos de pastagens e criação de ovelhas, para ofertar lã às indústrias têxteis nascentes na Inglaterra. Parte dessas propriedades foi arrendada e gerou capital para investimento nas indústrias. Desde então, os servos, vassalos e demais trabalhadores perderam o direito de retirar o seu sustento da terra, que era garantido no feudalismo, pelos donos dessas propriedades, pela Igreja Católica e pelo Estado (MARX, 2010).

As áreas de uso particular e comunal, inclusive aquelas de posse da Igreja Católica, utilizadas como bem comum para garantir trabalho e sobrevivência foram usurpadas dos camponeses, expulsos dessas propriedades pelos mais diversos meios violentos. $O$ parlamento que, inicialmente, foi contrário a essa expropriação, funcionou no século XVIII como importante mecanismo de suporte dessa ação violenta, instituindo leis sanguinárias destinadas aos cercamentos e arrendamentos do campo, quando a lei se transformou em veículo de roubo e concentração de terras nas mãos de poucos proprietários. Nas palavras de Marx (2010, p. 804),

O roubo dos bens da Igreja, a alienação fraudulenta dos domínios estatais, o furto da propriedade comunal, a transformação usurpatória, realizada com inescrupuloso terrorismo da propriedade feudal foram métodos idílicos da acumulação primitiva. Tais métodos conquistaram o campo para a agricultura capitalista, incorporaram o solo ao capital e criaram para a indústria urbana a oferta necessária de um proletariado inteiramente livre. 
O camponês sem os seus meios de trabalho tornou-se livre, mas teve que vender o uso da sua força de trabalho ao capitalista, para sobreviver. "A população rural, depois de ter sua terra violentamente expropriada, viu-se obrigada a se submeter, por força de torturas, à disciplina do sistema de trabalho assalariado" (MARX, 2010, p. 803). A resistência às condições desumanas de trabalho e a própria impossibilidade de a indústria absorver toda a massa de trabalhadores geraram o que o capital denomina "vagabundos" ou "vadios", que precisavam ser contidos pelas leis. Conforme Menegat (2002, p. 144), "amontoados em bairros segregados e habitando espaços insalubres, os destituídos de propriedade foram interpretados como o outro, inculto e incivilizado, cuja presença representava ameaça, sem precedentes, à ordem".

Mesmo que os trabalhadores tenham sido submetidos a toda a ordem de violência para fazer consolidar o capitalismo, essa classe lutou em favor desse modo de produção durante a Revolução Gloriosa na Inglaterra (1688), organizada para depor o monarca absolutista com plenos poderes sobre os direitos individuais (SIMÕES, 2009). Isso porque a referida revolução foi encenada como condição para aumentar a autonomia do indivíduo como principal agente de transformação das suas condições de vida. Essa revolução serviu para fortalecer "o pensamento ocidental" que atribuiu centralidade ao capitalismo, como grande defensor da liberdade dos indivíduos de acumular propriedade privada pelo trabalho (LUCIEN GOLDMAN, 1968 apud SIMÕES, 2009, p. 66). Os trabalhadores assumiram a condição de importantes protagonistas das revoluções que se espalharam pela Europa para lutar em favor da transição do feudalismo para o capitalismo, entendendo que esse modo de produção poderia gerar progresso e superar a opressão do modo de produção feudal.

A proposta de ampliar a liberdade dos indivíduos mediante a deposição dos governos absolutistas ganhou força na Europa e foi grande precursora da Revolução Francesa (1789), que contou com a "insurgência popular" para fortalecer "conceitos de justiça social, direitos humanos e voto universal" (SIMÕES, 2009, p.68). Conforme o referido autor, essa revolução foi a condição para a institucionalização dos direitos humanos, em 1789, formalizados a partir da Declaração dos Direitos do Homem e do Cidadão, que "reconheceu os direitos fundamentais de todos os indivíduos, pelo simples fato de serem humanos" (SIMÕES, 2009, P. 78). Regulamentou-se oficialmente a legitimidade dos direitos civis, como o direito de liberdade e de propriedade privada, necessários ao desenvolvimento do capitalismo.

Nessa direção, Simões (2009, p. 64) reconhece que os direitos políticos (fortalecidos com as revoluções) e civis (formalizados na Declaração dos Direitos do Homem e do Cidadão) foram necessários para que "a burguesia revolucionária estabelecesse nova estrutura econômica baseada na sociedade de mercado, na circulação de mercadorias e na institucionalização das 
relações contratuais de trabalho". Ou seja, que os direitos políticos e civis "forneceram as bases para o desenvolvimento da teoria dos direitos humanos, no século XX" e, inclusive, para a universalização dos direitos sociais no Brasil (SIMÕES, 2009, p. 72), principalmente, tendo em vista que a regulamentação dos direitos civis tornou a expropriação dos meios de sobrevivência do trabalhador um fenômeno ampliado, já que garantiu a "acumulação primitiva" dos europeus pela extração de riquezas em outros territórios (PRADO Jr, 1945 apud BARRETO, 2013, p. 24).

Em busca de expandir o seu poder, o capitalismo, já em pleno desenvolvimento na Europa, estendeu as suas fronteiras, alcançando a África, a Ásia e as Américas, pelo movimento que Milton Santos (2006) reconhece como globalização. Na perspectiva deste autor, a ideia de globalização que se inicia com as descobertas de novas rotas de navegação e de novos territórios para ampliar os mercados capitalistas instituiu novo padrão de relacionamento entre os povos. Os países deixaram a condição de estabilizados para se tornarem dependentes, na medida em que o capitalismo se estabeleceu como padrão de poder mundial que se organiza para dominar e controlar força de trabalho e recursos naturais, vitais à produção de mercadorias. Para o capital, não bastava apenas o lucro e a extração de mais-valia na Inglaterra e na Europa. Era preciso ampliar os seus poderes e as suas fronteiras de atuação e conseguir, em outros países, explorar grandes quantidades de suas riquezas e seus potenciais.

Quijano (2005) traz grande contribuição para pensarmos nos impactos que a consolidação do modo de produção capitalista traz para a América Latina e o Brasil. De acordo com esse autor, o domínio da Europa sobre o Brasil se fez pela "colonização" e "colonialidade do poder" que validaram o "eurocentrismo". Pela colonialização, para subjugar outros territórios transformados em colônia. Pela "colonialidade do poder", porque os processos de colonização envolveram mudanças estruturais na organização material da vida, mas, também, alterações no modo de pensar as coisas. A "colonialidade do poder" sustenta a ideia (individual e coletiva) do eurocentrismo, que atribui centralidade e superioridade ao europeu em relação a outros povos e localiza o Brasil como país subdesenvolvido, periférico e habitado por selvagens, sendo o desenvolvido o próprio europeu, e o centro do capital localiza-se em países de capitalismo central.

Esse convencimento que colocou a Europa em posição de centralidade foi necessário para mobilizar as classificações de raça, que identificaram características de superioridade entre os brancos e de inferioridade entre os índios e negros para a exploração das riquezas latinoamericanas. Conforme Quijano (2005), essa ideia de inferioridade de raça ligada ao negro e ao índio trata-se de uma invenção europeia para conquistar poder, dominação e hegemonia 
mundial, porque biologicamente não existem estudos que fundamentem qualquer tipo de superioridade de um povo sobre o outro, do ponto de vista biológico.

A Europa conectou superioridade, dominação e raça, em busca de articular formas históricas de controle do trabalho, de seus recursos e produtos. A questão racial precisou produzir idoneidades para saquear toda a riqueza de territórios latino-americanos durante o processo de expansão do capitalismo europeu, já que essa codificação de raças foi fundamental para que a metrópole portuguesa transformasse o negro em "moeda não metálica" necessária para extrair e acumular riquezas do território brasileiro, bem como "criar mecanismos para inibir o acesso à propriedade da terra à massa de mão de obra escrava" e aos destituídos de riquezas (BARRETO, 2013, p. 27-29). Essa subjugação do pensamento, que tem como referência a Europa, incapacitou um povo de pensar a si próprio, a partir de suas próprias ideias, concepções e particularidades. A “colonialidade do poder" é um elemento que permanece mesmo após o processo de independência do Brasil, em 1822. Mesmo que esse país tenha se tornado independente, não deixou de ser regido e comandado por poderes do capitalismo central vindos de fora que tornam ainda mais opressoras as políticas brasileiras que fazem a democracia retroceder. A institucionalização dos direitos civis sob a lógica do capitalismo foi condição para

[...] o acirramento dos conflitos trabalhistas nos séculos XIX e XX, a violência e a repartição internacional das riquezas, bem como para o desemprego crescente, o aumento da criminalidade, o abandono de criança e adolescentes, o racismo, o fanatismo religioso e o nacionalismo (SIMÕES, 2009, p. 66).

Portanto, a expansão do capitalismo industrial, permeada pelos direitos políticos e civis, foi a condição para o surgimento dos direitos sociais (segunda geração de direitos) institucionalizados para compensar as desigualdades sociais aumentadas desde então. Esses direitos foram garantidos inicialmente aos trabalhadores europeus, que "passaram a questionar a declaração formal dos direitos de liberdade e igualdade diante da pobreza e da expropriação a que foram submetidos", pressionando o Estado a deixar a condição de agente passivo para transformar-se em "formulador ativo de políticas públicas" (SIMÕES, 2009, p. 72-73).

\section{Assistência no Brasil: entre a universalização dos direitos sociais e a institucionalização da democracia participativa}

No Brasil, os direitos sociais foram regulamentados, principalmente, a partir de $1930 \mathrm{com}$ o desenvolvimento do capitalismo industrial e, também, se limitaram aos trabalhadores de alguns setores estratégicos da economia, quando o Estado se transformou em "principal sujeito na produção do desenvolvimento econômico". Essa proteção pública cresceu entre 1950 e 1980 ao 
lado do autoritarismo e da repressão do governo militar para conter os movimentos da sociedade civil que, inconformada com o aumento das desigualdades sociais, não deixou de pressionar o Estado em favor da universalização da proteção social.

Essa demanda foi atendida com a promulgação da Constituição Federal de 1988 "que incorporou" sob a forma de seguridade social "a previdência social, a saúde e a assistência social" (SILVA et. al., 2014, p. 28), quando os direitos sociais foram universalizados para atender a ampla massa da população e manter a dignidade humana que no Art. $1^{\circ}$ dessa Lei aparece "como um dos fundamentos do Estado democrático".

A universalização dos direitos sociais foi efetivada pelo comprometimento da Carta Magna com o Estado democrático de direito e o princípio da equidade, que justificou a criação de leis diferenciadas para "erradicar privilégios sociais" (SIMÕES, 2009, p. 75). Essa orientação legal foi condição para a formalização da assistência social como um direito de "quem dela necessitasse", que deveria ser garantido sem exigência de contribuição direta de renda, com a intenção de

Proteger à família, à maternidade, à infância, à adolescência e à velhice; amparar às crianças e adolescentes carentes; integrar ao mercado de trabalho; habilitar e reabilitar as pessoas portadoras de deficiência e promover sua integração à vida comunitária; garantir um salário mínimo de benefício mensal à pessoa portadora de deficiência e ao idoso que comprovem não possuir meios de prover à própria manutenção ou de tê-la provida por sua família (SIMÕES, 2009).

Além de reconhecer a assistência como direito social que deveria ser garantido aos desamparados, a Constituição de 1988 instituiu a democracia participativa e transferiu aos Conselhos nacional, estaduais e municipais, a responsabilidade pela administração coletiva da assistência social. Nessa direção, os municípios foram responsabilizados por "executar e controlar essa política, bem como fiscalizar o orçamento para a sua execução, tendo em vista o Plano Nacional de Ação da Assistência Social e o Fundo Nacional de Recursos Financeiros" (IDEM, 2009, p. 110).

A Carta Magna estabeleceu, ainda, que para essas deliberações, os Conselhos deveriam nomear membros do poder público e da sociedade civil, representados por "usuários das políticas de assistência social (associações comunitárias, clubes de mães etc.)" e pelas entidades e organizações sociais (creches, associações, movimentos comunitários, etc.) que "prestam serviços aos usuários" (SIMÕES, 2009, p. 109-110).

Para justificar a participação popular na construção de políticas públicas como um direito (quarta geração de direitos), a Constituição de 1988 reconheceu as "reinvindicações coletivas" (terceira geração de direitos), dando visibilidade às demandas, por exemplo, "de moradores em situação de rua, de trabalhadores integrantes de determinadas categorias profissionais e de 
usuários de certos serviços públicos” (SIMÕES, 2009, p. 77). Isso demonstra o quanto os trabalhadores foram importantes protagonistas nesse processo de conquista de direitos, já que participaram das revoluções europeias em favor do capitalismo, e também das mobilizações brasileiras para garantir a transição do regime militar à democracia liberal, a universalização dos direitos sociais e a participação da sociedade civil na formulação e controle das políticas sociais.

Codato (2005) confirma, por meios de dados estatísticos, a pressão dos trabalhadores para fazer implantar a democracia representativa no Brasil em 1985 e fazer promulgar a Constituição em 1988. Segundo o referido autor, entre 1978 e 1985, o número de greves aumentou muito no Brasil, e, no ano da democracia (1985), muitos trabalhadores pararam para pressionar o Estado burguês a introduzir mudanças em favor da população menos favorecida. Essas greves em contínuo crescimento duplicaram entre 1986 e o ano anterior ao ano de promulgação da Carta Magna, que universalizou os direitos sociais no Brasil, conforme tabela a seguir.

Tabela 1: Número total de greves, número médio de trabalhadores parados e média de dias parados, nas regiões urbanas.

\begin{tabular}{|c|c|c|c|}
\hline Ano & $\begin{array}{c}\text { Total de } \\
\text { Greves }\end{array}$ & Número Médio de Trabalhadores Parados & $\begin{array}{c}\text { Média de Dias } \\
\text { Parados }\end{array}$ \\
\hline 1978 & 118 & 1868 & 6,5 \\
\hline 1979 & 246 & 9777 & 6,6 \\
\hline 1980 & 144 & 9012 & 7,4 \\
\hline 1981 & 150 & 6107 & 8,8 \\
\hline 1982 & 144 & 4934 & 5,9 \\
\hline 1983 & 347 & 3689 & 4,4 \\
\hline 1984 & 492 & 2946 & 3,9 \\
\hline 1985 & 619 & 11016 & 6,3 \\
\hline 1986 & 1004 & 5181 & 5,8 \\
\hline 1987 & 2193 & 4187 & 8,2 \\
\hline
\end{tabular}

Fonte: http://www.scielo.br/scielo.php?pid=S0104-44782005000200008\&script=sci arttext

Apesar de toda a luta do trabalhador para regulamentar a democracia participativa em Conselhos de Assistência Social, o "processo de ampliação de direitos sociais rumo à universalização" enfrentou dificuldades de se efetivar desde o final da década de 1980 (SILVA et. al., 2014, p. 29), quando "o governo brasileiro, favorável à economia globalizada, adotou o projeto de desenvolvimento econômico, sob a orientação da ideologia neoliberal". Para investir em setores considerados mais dinâmicos da economia e elevar o potencial competitivo do Brasil no mercado mundial, o governo brasileiro desmontou o sistema de proteção social institucionalizado na Carta Magna, com justificativa de apoiar o progresso. Apesar de a proteção 
social e assistência ter assumido legalmente compromisso com a universalização, na prática não abandonou a orientação residual e compensatória. As medidas econômicas orientadas para o mercado (controle rigoroso da crise econômica, abertura comercial e financeira, privatização de empesas estatais, flexibilização do trabalho e precarização dos direitos sociais) tornaram insustentável a principal intenção da democracia participativa, de reduzir as desigualdades sociais. Nas palavras de Codato (2005, p. 1), "as reformas neoliberais tiveram como precondição o arranjo autoritário dos processos de governo" que limitou a construir a hegemonia social do capitalismo neoliberal.

Segundo lamamoto (2015, p. 117-147), mesmo regulamentada como um direito, a assistência social sob a lógica da sociabilidade capitalista tem sido submetida aos "ditames da política econômica" e privilegiado a qualificação para o trabalho, historicamente naturalizada como o meio mais legítimo e racional de geração da renda das famílias trabalhadoras e de financiar e garantir direitos sociais. Essa orientação tem permeado o trabalho na política de assistência social, que defende o trabalho aos capacitados e a assistência mínima aos incapazes.

Como uma política residual e focalizada, a assistência social não atende a todos aqueles com direito de acessá-la. Estabelece méritos para priorizar, dentre a população de baixa renda, aqueles desempregados e "incapazes de sustentar a si próprios" (COUTO, 2005, p. 673). Para Carnelossi (2016), a política de assistência social tende a assumir três características na contemporaneidade. Focalizam a pobreza e a extrema pobreza; exigem contrapartidas dos usuários geralmente nas áreas da educação e saúde; e legitimam a participação no mercado de trabalho como forma de reduzir a demanda por assistência, o que demonstra "uma ortodoxia moralista que nega aos trabalhadores a devida proteção, autorresponsabiliza os indivíduos e esvazia o Estado de seu papel” (PEREIRA, 2014, p. 20 apud CARNELOSSI, 2016, p. 2).

Essa perspectiva não leva em conta as contradições entre as classes sociais e não considera que a desigualdade existe por causa da subordinação do trabalhador ao capital, que tende a piorar em países periféricos. Orientadas por essa tendência, as decisões em conselhos de assistência social negam essa política como um direito e não problematizam a verdadeira causa da exclusão social. Nas palavras de Couto (2015, p. 673), "incorpora-se a ideia de a política de assistência social ter apenas um papel residual e compensatório e desloca-se do debate, a luta por investimentos na proteção social permeada pela redistribuição da riqueza socialmente produzida".

A discussão aqui proposta compreende a qualificação para o trabalho como mecanismo necessário para a sobrevivência na sociedade capitalista, já que os indivíduos precisam ter suas 
necessidades concretas atendidas para manter a sua vida. Entretanto, esse posicionamento não inviabiliza a importância de analisar criticamente porque o trabalho não tem dado conta de superar a pobreza e a política de assistência, como discutido em seguida.

\section{Trabalho como inclusão social?}

Karl Marx (2017) identificou o trabalho como determinante objetivo que garante a sobrevivência e existência do ser social em sociedade, já que em sua essência constitui a ação do homem de transformar a natureza e a si mesmo para atender as suas necessidades. Nas palavras de Marx (2017, p. 255), “agindo sobre a natureza externa e modificando-a por meio desse movimento, o homem modifica, ao mesmo tempo, sua própria natureza”. Para este teórico, no capitalismo esse trabalho concreto vai ser igualado e homogeneizado para produzir mercadorias para a troca e, nesse formato, apesar de necessário para a sobrevivência, o trabalho tem sido a causa das desigualdades sociais.

Conforme Marx (2017), no capitalismo, o trabalhador vende o uso da sua força de trabalho por um determinado tempo e o empregador remunera apenas o tempo socialmente necessário para a reprodução do trabalhador. Ou seja, remunera apenas parte dessa jornada de trabalho sob a forma de salário, calculado com base no atendimento mínimo das necessidades objetivas e subjetivas dessa mão de obra, no número de trabalhadores disponíveis para exercer essas funções e nas especificidades e períodos históricos de cada país. Nas palavras de Netto e Braz (2012, 116),

\footnotetext{
O salário é o preço da força de trabalho que, como qualquer outra mercadoria, é regida pela lei do valor. O valor da força de trabalho é determinado pelo valor exigido para produzir, desenvolver, manter e perpetuar a força de trabalho e, consequentemente, manter o capitalismo. O regime salarial contribui para difundir a falsa ideia, tão cara aos capitalistas, segundo a qual, mediante o salário, os trabalhadores obtêm a remuneração integral do seu trabalho. A falsa noção de que o trabalho remunera todo o seu trabalho é reforçada pelo fato de a jornada de trabalho ser contínua e de ele trabalhar com meios de produção que não lhe pertencem e num espaço físico que também é de propriedade do capitalista. Por isso, a maioria dos operários sente a exploração, mas não alcança na sua experiência cotidiana a adequada compreensão dela.
}

O capitalista compra matérias-primas, meios de produção e o uso da força de trabalho (mercadoria com característica especial) para produzir mercadorias em grande escala. Nas palavras de Netto e Braz (2012, p. 114-115), “a força de trabalho é denominada capital variável porque reproduz o seu próprio valor e cria um valor excedente. O capital constante produz maisvalia, mas não é condição suficiente, já que a mais-valia (valor) é criada exclusivamente pela exploração da força de trabalho". 
O trabalhador produz muito mais que o valor que recebe, para manter o trabalho excedente não remunerado, a acumulação de capital e a apropriação privada da riqueza socialmente produzida. Nas palavras de Netto e Braz (2012, p. 113-114), a força de trabalho comprada apresenta-se como mercadoria especial que o capitalista tem o direito de dispor de seu valor de uso, ou seja, da sua capacidade de trabalho para ganhar mais do que investiu. Então, "o salário representa sempre um montante de valor inferior ao produzido na jornada de trabalho". Nessa direção, Boschetti (2016) reconhece que, no capitalismo, o trabalho tem sido sinônimo de exploração, acumulação e desigualdade.

A ideologia que condiciona a inclusão social pelo trabalho ganhou força com os resultados da proposta do economista britânico John Maynard Keynes ${ }^{4}$, que contribuiu para aumentar a proteção social a partir do pleno emprego nos países de capitalismo central, após a crise ${ }^{5}$ de 1929-1930. O keynesianismo defendeu a intervenção do Estado para apoiar o desenvolvimento da indústria; elevar o número de mão de obra empregada e, consequentemente, estimular o consumo das mercadorias colocadas no mercado. De outro lado, para apoiar a administração dos impostos progressivos arrecadados com o pleno emprego formalizado, tornando mais qualificado os serviços públicos, financiados por trabalhadores e capitalistas (BEHRING e BOSCHETTI, 2011, p. 86).

Esse modelo que aliou desenvolvimento econômico com a ampliação de direitos trabalhistas e serviços públicos universais foi incentivado, segundo Behring e Boschetti (2011, p. 83), pelo fordismo ${ }^{6}$, que nesse período gerou um boom de "novos produtos e processos de produção" (BEHRING e BOSCHETTI, 2011, p. 114-115). As referidas autoras consideram que, também, foi favorável ao keynesianismo, a necessidade de o capitalismo se reinventar para se manter hegemônico durante a Guerra Fria (1945-1991) e demonstrar que a democracia liberalburguesa valia mais à pena do que o socialismo da União Soviética. Essas mudanças "davam a impressão de que o capitalismo havia encontrado a fórmula mágica, para combinar acumulação e equidade". Nas palavras de Behring e Boschetti (2011, p. 85),

\footnotetext{
${ }^{4}$ Preocupado em compreender a crise de 1929 e encontrar respostas para ela, Keynes em seu clássico livro "Teoria geral do emprego, do juro e da moeda", publicado em 1836, defendeu a intervenção estatal com vistas a reativar a produção.

${ }^{5}$ Essa crise teve início com a queda da bolsa de valores em Nova York. Configura-se uma superabundância de capitais e uma escassez de lucros, produzindo o desemprego generalizado e a queda do consumo, inviabilizando o processo de realização da mais-valia. Nessa forma de organização política, o nível de tensão entre as classes sociais, no qual a margem de discussão e negociação com a classe operária se reduz a patamares mínimos, não poderia se sustentar a médios ou longos prazos (BEHRING E BOSCHETTI, 2011, p. 69-71).

6 Os métodos criados em 1914 por Henry Ford serão de fato adotados no $2^{\circ}$ pós-guerra, colaborando para isso, o próprio esforço de guerra que disciplinou os trabalhadores nas novas formas de organização racional da produção, cujo objetivo final era diminuir a porosidade de tempo no âmbito da jornada de trabalho, otimizando o processo de valorização do capital (BEHRING; BOSCHETTI, 2011, p. 87).
} 


\begin{abstract}
O Estado tem legitimidade para intervir por meio de um conjunto de medidas econômicas e sociais, tendo em vista gerar demanda efetiva, ou seja, disponibilizar meios de pagamento e dar garantias ao investimento, até mesmo contraindo déficit público, para controlar o volume da moeda disponível e as flutuações da economia. Restabelecer o equilíbrio econômico, por meio de uma política fiscal, creditícia e de gastos, realizando investimentos ou inversões reais que atuem nos períodos de depressão como estímulo à economia.
\end{abstract}

Muitas propostas dos governos atuais tendem a se apoiar nesse modelo praticado por países de capitalismo central, para defender o trabalho como solução dos males sociais. Isso sem considerar as especificidades históricas do mercado de trabalho de cada país e levar em conta a insustentabilidade dessa proposta nos países desenvolvidos, que na década de 70 "não conseguiram escapar da recessão profunda ou da inflação acentuada" (BEHRING E BOSCHETTI, 2011, p. 116-117), causadas pelo intenso emprego de tecnologias; pela elevação da produtividade; pela superacumulação de mercadorias que demitiu muitos trabalhadores e pela dificuldade que o capital teve de aumentar a extração de mais-valia de trabalhadores mais conscientes de seus direitos e mais resistentes à exploração, quando começaram a problematizar a sua condição na relação com o capitalista (IDEM, p. 117-118).

Conforme Behring e Boschetti (2011, p. 116), a recessão do capitalismo entre 1974 e 1975 reforça a insustentabilidade desse modo de produção, desqualificando os argumentos que defendem o trabalho como condição de controlar as crises do capital. As referidas autoras citam Mandel (1990), segundo o qual as crises são centrais do capitalismo como "um sistema constituído de tensões, rupturas e continuidades" (MANDEL, 1985 apud ORTIZ, 2010, p. 24).

Boschetti (2016, p. 116) retoma Mandel (1990, p. 214) para explorar aspectos de fragilidade do capitalismo associados à busca contínua do capital por lucro. Para Mandel (1990), os capitalistas tendem a investir em tecnologias e inovações para produzir mais mercadorias em tempos de crescimento da economia. Mesmo substituindo trabalho vivo (trabalhadores) por trabalho morto (equipamentos), o capitalista consegue, inicialmente, em decorrência da produção aumentada de mercadorias, elevar a mais-valia expropriada do trabalhador, reduzir preços de matérias-primas e elevar o total de capitais. Mas, essa expansão por longo prazo tende a reduzir o exército industrial de reserva e a dificultar a extração de mais- valia da mão de obra mais consciente de seus direitos; elevar os preços das matérias-primas e fazer o lucro decair. Com essa configuração, a economia eleva a concorrência entre as empresas, que passam a ter mais dificuldade de aumentar a extração de mais-valia e, consequentemente, os seus lucros. Principalmente, em contexto de substituição do trabalho vivo (que gera valor) pelo trabalho morto (máquina), o dinheiro em circulação aumenta, mas diminui o valor permeado pela exploração da mais-valia. Nas palavras de Mandel (1990, p. 216), "o superinvestimento provoca uma 
superacumulação, que, por sua vez, gera um subinvestimento e uma desvalorização massiva de capitais".

Então, apesar de a qualificação ser necessária para aumentar possibilidades de inserção no mercado de trabalho e garantir a sobrevivência no capitalismo, não dá conta de eliminar a assistência social, principalmente, em países periféricos.

\section{Trabalho em países periféricos}

No Brasil, por exemplo, o mercado de trabalho historicamente não tem dado conta de absorver toda a sua mão de obra ativa disponível e ofertar postos de trabalho que garantam condições seguras de vida. Segundo Ricardo Antunes (2009; 2018), estudioso do trabalho na América Latina, o mercado formal dessa região do continente americano nunca deu conta de absorver toda a força de trabalho e tem ofertado empregos cada vez mais precarizados.

De acordo com Pedroso (2015), quando a industrialização brasileira precisou ser apoiada em princípios do século XX, por causa da crise da economia rural, a autoridade dos primeiros industriais oriundos da elite agrária delineou os direitos instáveis da nova classe de assalariados. O trabalhador formal desse setor foi submetido à "superexploração" para elevar a lucratividade dos industriais e manter a concentração de renda nas mãos desses capitalistas (PEDROSO, 2015, p. 129). Principalmente, quando a industrialização brasileira passou a contar com mais capital estrangeiro para o seu desenvolvimento e os países de capitalismo central, em crise, avançaram em direção aos países periféricos para "produzir novos espaços para a exploração capitalista" (IAMAMOTO 2015, p. 111-112). As condições dos trabalhadores pioraram com a subordinação da economia brasileira "à dinâmica capitalista internacional”, quando aumentou o fluxo de capitais que chegavam do estrangeiro ao mercado brasileiro, a partir da década de 1950, para ser investido na indústria de energia e siderurgia (ORTIZ, 2010, p. 53).

As condições dos trabalhadores pioraram porque, com grande potencial para criar inovações, os países desenvolvidos são mais favorecidos na relação comercial com os países periféricos. Marini (2011) reconhece essa relação como desigual e combinada devido ao fato de, para manter benefícios dos países que dominam o mercado de tecnologias, os países em desenvolvimento precisam continuar exportando produtos primários, menos valorizados do que as manufaturas que importavam. Com essa configuração, esse comércio internacional impacta negativamente no mercado de trabalho brasileiro na medida em que, para compensar as perdas dessa negociação, as nações desfavorecidas intensificam a exploração do trabalhador. Essa força de trabalho sub-remunerada é submetida a uma jornada mais intensa de trabalho para 
manter a apropriação de mais tempo de trabalho excedente pelos capitalistas. Por isso, segundo Pedroso (2015, p. 123), a industrialização brasileira e a inclusão de mais mão de obra no mercado formal de trabalho não implicaram na ampliação dos direitos sociais dos trabalhadores.

Em busca de ampliar espaços de dominação, os países centrais contaram com o suporte de agências multilaterais (Organização Internacional do Trabalho, Fundo Monetário Internacional, Organização das Nações Unidas) para o disciplinamento dos países periféricos à nova ordem capitalista (MARINI, 2011, p. 213). Conforme este autor, em 1950 a ONU incentivou a formação de comissões como a CEPAL (Comissão Econômica para a América Latina e o Caribe), que defendeu a necessidade de investir tecnologias nas indústrias dos países em desenvolvimento, para que esses deixassem de ter prejuízos nas relações comerciais com os países centrais (MARINI, 2011). Foi quando a CEPAL propôs solucionar os problemas sociais por meio da "competitividade empresarial, liberdade de ação dos capitais privados e integração subordinada a algum bloco econômico, estava construindo os grandes centros capitalistas", via exploração do trabalhador (MARINI, 2011, p. 215).

Esse debate também foi encaminhado por Rosângela Nair de Carvalho Barbosa (2007, p. 60), que argumenta sobre o aumento da transferência de tecnologias dos países centrais ao Brasil a partir da década de 1950, sob a justificativa de tornar as indústrias brasileiras mais competitivas. Barbosa (2007, p. 62) informa ainda, a partir de Moretto (2003, p. 242-243), que essa inovação não teve êxito, já que "as promessas de crescimento duradouro não se realizaram, a taxa de desemprego aumentou, o volume de renda do trabalho na soma nacional recuou, e a variação do PIB foi uma das piores".

Esses resultados, conforme Marini (2011, p. 141; 145), têm a ver com a "oferta de matérias-primas industriais" aos países da periferia, que incentivou a substituição do trabalho vivo pelo trabalho morto, elevando o número de trabalhadores ativos desempregados. De outro lado, Ortiz (2010, P. 29) reconhece que as vantagens dos países centrais não deixaram de existir e foram mantidas pelas "pesquisas e inovações tecnológicas como fonte permanente de extração de superlucros e ampliação de mercados”. Essas inovações serviram para piorar o mercado de trabalho brasileiro, que historicamente investiu pouco na indústria de bens de capital e precisou depender, ainda mais, dos países centrais.

Com a crise econômica dos países centrais em 1970 e a submissão da economia brasileira, ao longo de 1980, aos planos de escalonamento da dívida estatal, os trabalhadores brasileiros foram mais explorados. Para pagar a dívida e manter o fluxo de captais estrangeiros, o Estado restringiu o seu apoio à indústria brasileira e muitas empresas decretaram falência. $O$ crescimento do exército industrial de reserva tornou os empregados ainda mais submissos a 
todas as imposições do capital, para cumprir um "ritmo intenso de trabalho e horas extras" (PEDROSO, 2015, p. 129).

Os postos de trabalhos formais ampliados entre 1950 e 1980 deixaram de crescer com a crise econômica e o endividamento externo. De outro lado, a massa de desempregados e dos trabalhadores informais aumentou ainda mais a partir de 1990, com a globalização, que favoreceu as transações comerciais realizadas em âmbito mundial e a transferência da política neoliberal aos países da periferia (BARBOSA, 2007). Esta política apresentada como modelo necessário em tempos de estagnação da economia tem impactado negativamente no mercado de trabalho, na medida em que propõe a privatização para reduzir gastos estatais; a flexibilização das formas e dos rendimentos do trabalho para aquecer a economia; e a paralisação dos movimentos operários que reivindicam direitos sociais (IAMAMOTO, 2015, p. 116). Segundo Antunes (2009, p. 113; 120), a sociedade do capital e sua lei do valor mantêm-se cada vez mais pelo trabalho "parcial, terceirizado, precarizado, informal, sem direitos e submetido ao sistema perverso de metas, e imposto para devastar a legislação trabalhista no Brasil”.

O desmonte dos direitos trabalhistas no Brasil tem sido funcional às multinacionais que se instalaram em território brasileiro, principalmente, após a Segunda Guerra Mundial, em busca de mão de obra com custos reduzidos. Também é interessante à indústria nacional que busca subsídios na exploração do trabalho precário, flexível e terceirizado para se manter competitiva no mercado mundial. Essas modificações "agravaram ainda mais as características históricas de baixos salários, alta rotatividade de mão de obra e escassez de postos de trabalhos formais, que já deixava de fora parte expressiva da população economicamente ativa (PEA)" (PEDROSO, 2015, p. 162).

Mesmo que no final da década de 1980 o trabalhador tenha conseguido aumentar o seu poder de reivindicação com a transição da Ditadura-Militar para a democracia e conquistar direitos trabalhistas com a Constituição de 1988, muito pouco foi efetivamente feito para melhorar as condições de trabalho desumanas dessa classe. Esse movimento de perda de direitos para o trabalhador brasileiro ganhou mais dinamismo a partir de 2017, com a lei da terceirização e as propostas de reforma trabalhista que, segundo Antunes (2017), alterou 117 textos dos 900 artigos da Consolidação das Leis Laborais.

O trabalho flexível que era uma relativa exceção tem se transformado em regra. Antunes (2018) apresenta as estatísticas do Instituto Brasileiro de Geografia e Estatística (IBGE) para informar que "entre outubro e dezembro de 2017, 598 mil trabalhadores (5,7\%) a mais do que no mesmo trimestre de 2016 trabalhavam como informais. No terceiro trimestre (julho a setembro) de $2017,1,1$ milhão de pessoas $(4,8 \%)$ a mais do que no mesmo trimestre de 2016 trabalhavam 
por conta própria. Números esses que podem, conforme o referido autor, aumentar caso a taxa de desocupação mantenha o seu crescimento, que está em progressão desde 2014".

O trabalho como condição de exploração do trabalhador para a acumulação capitalista não reduz as desigualdades de classe. No tópico seguinte, buscou-se discutir em que medida privilegiar o trabalho nos conselhos gestores de políticas sociais tem desqualificado a democracia participativa.

\section{Democracia participativa em Conselhos de Assistência Social}

A universalização dos direitos sociais, a institucionalização da assistência e a regulamentação da democracia participativa para deliberar sobre essa política compreendem medidas instituídas com a expansão do Estado Social para amenizar as condições das desigualdades. Entretanto, a democracia participativa não tem dado conta de alcançar essa proposta, por causa das configurações que assume no capitalismo.

Boschetti (2016) denomina burguesa a democracia criada sob a sociabilidade capitalista que mantém a exploração do trabalhador em favor da acumulação de capital (IDEM, 2016, p. 48). Por essa perspectiva, a autora reconhece que a "cidadania burguesa" se faz pelas conquistas de direitos sociais que beneficiam o trabalhador, sem deixar de privilegiar o capitalista. Argumenta ainda que, sob essa sociabilidade, mesmo a democracia mais aperfeiçoada tem alcançado a emancipação política e não a emancipação humana. Nas palavras de Boschetti (2016, p. 56),

\footnotetext{
A emancipação política é o reconhecimento dos direitos no âmbito do Estado político, do Estado como república, sem que isso implique em qualquer superação das relações capitalistas. O cidadão pode ser reconhecido como cidadão político, ou nos termos marshallianos, adquirir status político de cidadão, sem se libertar das condições objetivas que o obrigam a vender sua força de trabalho.
}

Boschetti (2016) introduz a teoria de Marshall que trata da institucionalização dos direitos sociais na Inglaterra no século XX (Keynesianismo) como marco da cidadania completa. Como Marshall (1967, p. 77), Boschetti (2016, p. 84) reconhece que a regulamentação do Estado social garante a conquista de direitos pelo trabalhador como cidadão. Mas, ao contrário de Marshall, não compreende nessa conquista a possibilidade de "garantir a liberdade e a igualdade da verdadeira emancipação humana" (BOSCHETTI, 2016, p. 58), na medida em que a democratização dos direitos sociais mantém a relação entre capital e trabalho e as desigualdades de classe, que obrigam o trabalhador a continuar vendendo o uso da sua força de trabalho como mercadoria. 
Nessa direção, Ortiz (2015, p. 73) analisa criticamente o "projeto da democracia das massas", fundamentado na "crença de construção de uma nova ordem societária por dentro das instituições democráticas burguesas". Para a autora, essa democracia como expressão do liberalismo possibilita ao trabalhador "disputar a direção política, ideológica e cultural do Estado e de suas instituições", mas não deixa de privilegiar "interesses burgueses" (TOLEDO, 1994, p. 35 apud ORTIZ, 2015, p. 74). Já que "a democratização das relações existentes no modo de produção capitalista mantém o desenvolvimento das forças produtivas em harmonia e, portanto, tem sido útil para a reprodução o capitalismo" (ORTIZ, 2015, p. 76).

Essa análise ajuda a entender porque os Conselhos Municipais de Assistência tendem a privilegiar o trabalho como forma de emancipação do sujeito social e pensar nos limites desse direcionamento. Essa perspectiva tem limitado a democracia participativa nessas instâncias de decisões públicas em pelo menos duas direções. Mantém a expropriação do trabalhador em favor da acumulação capitalista e torna inoperante o objetivo de reduzir as desigualdades sociais mediante "acordos argumentativos" entre poder público e sociedade civil (COHEN, 1999, p. 73 apud LUCHMANN, 2006, p. 22).

A qualificação para a inserção no mercado trabalho, como objetivo mais valorizado da política de assistência, não supera a pobreza, a fome e o desemprego porque é o próprio trabalho produtivo que mantém essas condições de exclusão social, porque "quanto mais precarizado o mercado de trabalho, maior será a necessidade de demandas por assistência social" (BOSCHETTI, 2016, p. 107). Com esse formato, a política de assistência não tem conseguido assumir compromissos com o princípio da equidade, que tem perdido a sua eficácia na prática, quando colocado sob a lógica do capitalismo.

Ao invés de analisar a exclusão social como condição do modo de produção capitalista que deve ser administrada pelo Estado, os conselhos municipais de assistência social tendem a responsabilizar os pobres desempregados e as despesas com a assistência pela crise econômica e social. Essas instâncias de decisão transferem à sociedade civil "a responsabilidade das ações voltadas para a área social num processo de desresponsabilização do Estado", e a assistência se transforma em prática filantrópica e solidária que deve ser mantida como iniciativa da sociedade civil (LUCHMANN, 2006, p. 23).

Dessa forma, porque a desigualdade e a pobreza no sistema capitalista aumentam com o trabalho produtivo, a política de assistência deve ser tratada em sua totalidade, como direito e universalizado para mais usuários. E, para garantir menores prejuízos ao trabalhador, a democracia como emancipação política deve ser incentivada, como propõe Marx (2010), na sua obra sobre a questão judaica. Este teórico (MARX, 2010, p. 87) entende "a emancipação política 
como um grande progresso" que deve ser "transgredido para prolongar o movimento de emancipação rumo à sua plenitude". Mas, de qualquer maneira, não deixa de se referir "à emancipação política, às liberdades formais e aos direitos democráticos como conquistas preciosas numa perspectiva história, dentro da ordem mundial vigente".

Principalmente, porque ampliar os direitos sociais dos trabalhadores significa fazer vir à tona a causa concreta das desigualdades sociais e redistribuir a riqueza socialmente produzida, transferida das mãos dos capitalistas ao fundo público, sob a forma de impostos, para financiar direitos sociais. A participação nos espaços de democracia pode significar aumento da pressão sobre o Estado, que passa a ter que administrar reinvindicações tanto da burguesia quanto da classe trabalhadora, e o poder deixa de ser exclusivo da burguesia.

Nessa direção, ganha relevância a proposta de democracia que Gohn (2011) denomina revolucionária e radical. Essa autora se apropria do debate de Boaventura de Sousa Santos (1999) para propor a participação nas instâncias de democracia deliberativa, das massas coletivas organizadas. Ou seja, dos "cidadãos ativos, politizados, com visão crítica da realidade, conhecedores dos problemas que os circundam e com compreensão sobre as causas e as origens desses problemas". Com maior potencial por "construir proposições e fazer denúncias que possam corromper o sentido e o significado do caráter público das políticas" (GOHN, 2011, p. 47-48).

\section{CONSIDERAÇÕES FINAIS}

Este ensaio teórico problematiza o tema da democracia participativa como expressão dos direitos humanos sob a lógica da sociabilidade capitalista. Para alcance deste objetivo, o conteúdo deste artigo foi distribuído entre introdução, considerações finais e mais um tópico que expõe a tese defendida.

O debate inicialmente contextualizou a expansão dos direitos humanos associada à transição do feudalismo ao modo de produção capitalista. Este tópico faz considerações sobre a institucionalização dos direitos humanos a partir dos direitos civis e políticos; apresenta a formalização dos direitos sociais condicionada à legitimidade do trabalho no capitalismo; contextualiza a universalização dos direitos sociais associada ao direito à assistência social e da gestão democrática desse direito em Conselhos de políticas públicas e, por fim, informa sobre fragilidades dessa democracia participativa que não tem alcançado o seu objetivo de reduzir a desigualdade social, na medida em que tem privilegiado, no conjunto dos objetivos da política de assistência, a qualificação para o trabalho. 
A partir da contextualização do processo de conquista dos direitos humanos, o texto expõe argumentos para realçar porque o trabalho no capitalismo não pode superar a política de transferência de renda. Nesse debate foram levados em conta os aspectos da exploração do trabalho produtivo, das crises do capitalismo; da precarização do trabalho improdutivo; das desigualdades de classe e do capitalismo dependente.

Em seguida, o texto problematizou a democracia a partir dos argumentos construídos anteriormente, enfatizando porque a democracia participativa dos Conselhos municipais de políticas públicas, sob a lógica da sociabilidade capitalista, tem proposto a qualificação pelo trabalho e em que medida esse posicionamento tem imobilizado possibilidades de emancipação humana do trabalhador. Por fim, em busca de fortalecer mecanismos de luta dos trabalhadores em favor da universalização da política de assistência social como um direito, este debate tratou de realçar a necessidade dos movimentos sociais organizados na emancipação política.

Contudo, este ensaio teórico analisa criticamente limites da democracia participativa sob a lógica da sociabilidade capitalista, para demonstrar porque a mesma não tem conseguido alcançar o objetivo pela qual foi institucionalizada. Os direcionamentos teóricos trazidos para o debate não desconsideram o trabalho como meio necessário para a subsistência das famílias no capitalismo, mas procurou-se analisar criticamente o quanto o trabalhador pode fazer expandir ou retroceder a proposta da democracia.

\section{REFERÊNCIAS}

ANTUNES, Ricardo Antunes. Os sentidos do trabalho: ensaio sobre a afirmação e a negação do trabalho. São Paulo, Boitempo, 2009.

ANTUNES, Ricardo Antunes. O privilégio da servidão: o novo proletariado de serviços na era digital. São Paulo: Boitempo, 2018.

BARRETO, Ana Cláudia de Jesus. O lugar dos negros e pobres na cidade. Juiz de Fora: UFJF, 2013.

BARBOSA, Rosangela Nair de Carvalho. A economia solidária como política pública: uma tendência de geração de renda e ressignificação do trabalho no Brasil. São Paulo: Cortez, 2007.

BOSCHETTI, Ivanete. Assistência social e trabalho no capitalismo. 4ํaㄹ. edão Paulo: Cortez. 2016.

BEHRING, Elaine Rossetti; BOSCHETTI, Ivanete. Política Social: fundamentos e história. Traduzido por Roberto Leal Ferreira. 9. ed. São Paulo: Cortez, 2011.

BRAZ, Marcelo; NETTO, José Paulo. Economia política: uma introdução crítica. $8^{a}$ ed., São 
Paulo: Cortez, 2012.

BRASIL. Constituição Federal de 1988. Disponível em: < https://www2.senado.leg.br/bdsf/bitstream/handle/id/518231/CF88_Livro_EC91_2016.pdf>. Acesso em: 10 mar. 2020.

CARNELOSSI, Bruna. O trabalho do assistente social no Programa Bolsa Família: desafios ao Código de Ética profissional. Serviço Social \& Sociedade, n.125, jan./abr. 2016, p. 1-12, São Paulo. Disponível em: <http://www.scielo.br/scielo.php?script=sci_arttext\&pid=S010166282016000100124>. Acessado em 5 de jan. 2019.

CODATO, Adriano Nervo. Uma história política da transição brasileira: da ditadura militar à democracia. Revista de Sociologia e Política, n.25, nov. 2005, Curitiba. Disponível em: <http://www.scielo.br/scielo.php?pid=S0104-44782005000200008\&script=sci arttext>. Acessado em 5 de jan. 2019.

CÔRTES, Soraya M. Vargas. Arcabouço histórico-institucional e a conformação de conselhos municipais de políticas públicas. Educar, n.25, nov. 2005, p. 143-174, Curitiba. Disponível em: <http://www.scielo.br/pdf/er/n25/n25a10.pdf>. Acessado em 5 de jan. 2019.

COUTO, Berenice Rojas. Assistência social: direito social ou benesse? Serviço Social \& Sociedade, n.124, out./dez. 2015, p. 665-677. Disponível em:

<http://www.scielo.br/pdf/sssoc/n124/0101-6628-sssoc-124-0665.pdf>. Acesso em: 10 mar. 2020.

DAHL, Robert A. A democracia e seus críticos. Traduzido por Patrícia de Freitas Ribeiro. São Paulo: Editora WMF Martins Fontes, 2012.

QUIJANO, Anibal. Colonialidade do poder, eurocentrismo e América Latina. CLACSO, Consejo Latinoamericano de Ciencias Sociales, Buenos Aires, 2005, p.117-142. Disponível em: <http://biblioteca.clacso.edu.ar/clacso/sur-sur/20100624103322/12_Quijano.pdf>.

GOHN, Maria da Glória. Conselhos gestores e participação sociopolítica. 4ª ed., São Paulo: Cortez. 2011.

IAMAMOTO, Marilda Villela. Serviço social em tempo de capital fetiche: capital financeiro, trabalho e questão social. 9aㅗ ed., São Paulo: Cortez. 2015.

LUCHMANN, Lígia Helena Hahn. Os sentidos e desafios da participação. Ciências Sociais Unisinos, n.42, jan./abr., 2006, p. 19-26, Santa Catarina. Disponível em:

<file:///C:/Users/Cristiane/Downloads/6011-18473-1-SM.pdf>. Acessado em 5 de jan. 2019.

MARINI, Ruy Mauro. Vida e obra. 2a ed., São Paulo: Expressão Popular, 2011.

MARX, Karl. O capital: crítica da economia política. 2ª ed., São Paulo: Boitempo, 2017.

MARX, Karl. O capital: crítica da economia política. São Paulo: Boitempo, 2010.

MARX, Karl. Sobre a questão judaica. São Paulo: Boitempo, 2010.

MENEGAT, Elizete. Questão social e segregação sócio-territorial: termos indissociáveis da crise do modelo de urbanização ocidental. Juiz de Fora: LIBERTAS, v. 2, 2002. 
ORTIZ, Fátima Grave. Democracia e Serviço Social: uma análise preliminar sobre as implicações das concepções marxistas e marxiana da democracia para a profissão. SER Social, Brasília, v. 17, n. 36, p. 68-83, jan.-jun., 2015. Disponível em:

$<$ file://C:/Users/USUARIO/Downloads/13416-Texto\%20do\%20artigo-23878-1-1020180918\%20(1).pdf>. Acesso em: 20 dez. 2016.

ORTIZ, Fátima Grave. O Serviço Social no Brasil: os fundamentos de sua imagem e da autoimagem de seus agentes. Rio de Janeiro: E-papers, 2010.

PEDROSO, Márcia Naiar Cerdote. 0 trabalho e suas transformações: um olhar sobre o Brasil no século XX. Bauru, São Paulo: Canal 6, 2015.

POCHMANN, Marcio. Proteção social na periferia do capitalismo: considerações sobre o Brasil. São Paulo em Perspectiva, v. 18, n. 2, São Paulo, abr./jun., 2004. Disponível em: < http://www.seade.gov.br/wp-content/uploads/2014/07/v18n2.pdf>. Acesso em: 20 dez. 2016.

SANTOS, Milton. O dinheiro e o território. In: SANTOS, Milton; et. al. Território, territórios: ensaios sobre o ordenamento territorial. Rio de Janeiro: DP\&A, 2006.

SANTOS, Milton. Por uma globalização: do pensamento único à consciência universal. 7ª ed., Rio de Janeiro: Record, 2001.

SILVA, Maria Ozanira Silva de; YAZBEK, Maria Carmelita; GIOVANNI, Geraldo di. A política social brasileira no século XXI: a prevalência dos programas de transferência de renda. $7^{a}$ ed., São Paulo: Cortez. 2014.

SIMÕES, Carlos. Curso de direito do Serviço Social. 3a ed., São Paulo: Cortez. 2009. 